The radio is a popular means of continuing education, with the BBC Foreign Service and Voice of America providing a regular source of spoken English and international news. The full tragedy of the recent events in Beijing will reach the quieter parts of the country only by overseas broadcasts. The disparity between these broadcasts and the domestic coverage of the civil unrest is unlikely to be the theme for discussion in the English conversation classes this term or the next as searches, arrests, and executions are carried out with considerable fervour. With the loss of public freedom of expression will come an alarming restriction of individual liberties as fear grows of being reported for "pro-democracy" sympathies, be they street demonstrations or casual conversations. The staff and students at the medical school will have an uncomfortable few years trying to work with academic freedom but with little opportunity of expressing it.

The distance and difference from home give the traveller a refreshing perspective on the migration taking place many miles away. The decision to return to join it becomes cortical rather than subthalamic. Whether the experience of such an adventure will help or hinder my future applications for jobs at home I do not know. It offers a ready excuse for anyone to put my application in the "far out" tray. I take this opportunity to refer my future employers to the "last page" of the Oxford Handbook of Clinical Specialties, "Let him never miss an opportunity to travel; and let him above all be alert and curious - for then he may gain a priceless therapeutic asset: a rich and compassionate personality."

\title{
How to encourage a referee: use your word processor carefully
}

\author{
Hugh Dudley
}

In a paper in the $B M \mathcal{F}$ last February John Ainslie wrote about how to choose a word processor and get it installed.' Judging by the manuscripts that I look at for the $B M \mathcal{F}$, however, many users seem not to know how to drive their systems and the journal's editorial staff are clearly saintly in their forbearance over the quality of manuscripts that are received. The premisecorrect, I suppose-is that the content rather than its presentation is the more important feature of a scientific paper. Hidden inside an incomprehensible manuscript typed on a pre-first world war Smith Corona loaded with a ribbon dipped in tar could be the idea of the century. I read 12-15 manuscripts a week and sympathise with the subeditorial staff, who have to put to rights the manuscripts that are accepted for publication. My conclusion is that greater discipline is required from authors.

I have also gained the definite impression that, since the advent of word processing, standards of presentation have gone down. Doubtless this decline has been accelerated by the almost universal demise of those stalwart, permanent, dedicated secretaries who used to exist in nearly every department. They have not been replaced by word processing packages. Indeed, word processing requires a new set of skills, and mastering them is not aided by the opacity of many of the instruction manuals. There is a paradox between the precision required to program a computer and the imprecision and sheer incomprehensibility of most of the explanatory manuals for both hardware and software. Nevertheless, I am amazed how anyone-let alone departmental heads, who should not only know better but also set their sights higher-can be pleased with most of the manuscripts that I have to peruse. Furthermore, though the principle of content before appearance must be honoured, readers and editors, be they ever so impartial, cannot help but be subtly and possibly unconsciously influenced by the way the work is presented: if the manuscript is sloppy perhaps the work is too?

Here then are some matters that over the past year have seemed to me to stem largely from the careless use of word processing packages, by which I mean both the hardware and the software because the two are intimately related. Mother Wing, St Mary's Hospital, London W2 1NY Hugh Dudley, СHм, emeritus professor of surgery
Ainslie's advice, than that the whole system is properly configured-a jargon term that embraces matching the machine's operating system to the machine itself; making sure that the machine and the printer are correctly matched; and doing the same for the word processing program so that it knows the printer with which it is communicating.

True, these three things should have been done when the computer and printer were installed, but there is ample evidence in submitted manuscripts either that configuration has not been properly done or that since it was done somebody has changed the printer or the word processing system, which now interacts differently with, for example, the printer. In the past part of the trouble lay with the rather difficult form in which the "set up" routines were presented, but now most are step by step (menu driven) and easy to follow. There is no excuse for writers-even if they subcontract the actual production of a manuscript to their secretary/wife/husband/research fellow-being ignorant of the configuration of their system; they should at least be able to check how it is set up. Many will say that they do not have sufficient knowledge of how computers work and do not intend to acquire the ability to understand. It is tenable that knowledge of the internal details of both hardware and software is unnecessary, but what I am getting at is that, though we do not need to understand the exact mechanics of power steering and antilocking brakes, we still need to know what effect they have on driving technique before we are let loose on the road. Configuration seems to break down particularly in matching up the printer to the computer, and it is always worth while getting a local expert to run through the printer configuration with you to make sure that you have got the correct routines installed. You need the expert in order to traverse some of the steep cliffs of jargon that still appear in even the most step by step installation procedures.

\section{Justified manuscripts}

We are all comfortable reading newspaper columns with a neat, straight right margin at which hyphenation makes sense. The skills of the old compositors meant that justification and hyphenation were almost faultless, but it will not have escaped most people's attention that even the sophisticated equipment available in Wapping and elsewhere does not always avoid large gaps between words or sentences to achieve 
right justification and that sometimes the computer makes a nonsense out of hyphens. Not surprisingly, the word processing packages available for most microcomputers are even less able to avoid similar disasters, and it is common to see an airy text in which the distance between successive words varies by up to several character widths and punctuation marks drift away from the words that they follow (fig 1). I find that this makes for uneasy reading, though maybe I am oversensitive.

There is an element of excitement also . Urgent surgery, the surgery of accident and of war, is often undertaken in circumstances of high drama-witness recent and regrettable

disasters in this country and abroad. However, much as we think them deplorable, they heighten the intensity of experience of those involved and often bring out the very best in people.

FIG $1-\mathcal{F}$ ustified (top) and unjustified sentences (bottom). Note uneven gaps between words in justified version

Worse is the unthinking nature of line breaks so that, for example, a bracket may appear as the last character on a line (with the parenthetical statement starting on the next) or a full stop may be in lonely isolation at the start of a line (fig 2). Sometimes the appearances are amusing but usually they are downright annoying. It can be argued, of course, that no decent typist would let such things stand, but it is evident that the friendly "temp" (often working permanently in the office but still without any commitment to excellence) frequently does. The appearance of such infelicities in manuscripts also makes it apparent that the author is insensitive or does not check a final draft. The best remedy of these problems is not to use right justification and hyphenation at manuscript stage. A "ragged right" is what most people are accustomed to in letters and other documents, so why ape the newspaper or the publisher?

Brown and his colleagues have given us the best information the matter is well approached by reading their publication of 1985). They deal most adequately with the methods and results Moreover they show us how to prosecute the matter furth-

FIG 2-Infelicitous line breaks

\section{Position of text on the page}

A properly configured system will position text on the page automatically so it is possible to get it right once and for all at the beginning. Getting it right is largely a matter of trial and error-shifting the position of the paper feed in the printer and also the software controls on the word processing package until you are satisfied. Cooperation between the writer and his or her secretary is vital. Modern word processing systems that allow you to view a page as it will appear in the manuscript before it is printed are a help, but again you have to wrestle (not with each other) until you get it right. The importance of all this is twofold. Firstly, a well balanced page is easy to read, and if an editor is a stickler for the Vancouver style-which lays down margin widths - he or she may be irritated by a manuscript that flagrantly does not conform. Secondly, if large spaces are left at the top and bottom and very wide margins are used these increase the bulk of the manuscript, so producing a reflex groan from the reader when in fact the number of words may not be all that large.

\section{Spelling checkers}

John Ainslie commented on spelling checkers as being well worth having. There is no doubt in my mind that it is more difficult to pick up spelling errors on a screen than in a manuscript. I am not sure why this is so, but it may just be that we have yet to become sufficiently familiar with the screen and the contrast between the displayed and the written or printed word. Also, if you type your own manuscripts, as many people either prefer or are forced to do, more mistakes are bound to occur than if a professional typist types them. I strongly recommend getting a package with a spelling checker built in, though remember that when you type, for example, "there" when you mean "their" the package will ignore the mistake because both are acceptable words. As an example of the usefulness of a spelling package, after I thought that I had the manuscript for this article right the checker turned up eight literals.

\section{Quality of printer}

The printer is, as John Ainslie explained, most likely to be a dot matrix one. In this a series of pins indents on to a ribbon to produce each character according to instructions fed from the computer. It is an amazing electromechanical instrument and properly handled can produce beautiful results. In general terms, however, the faster such printers are driven and the larger the typeface they are asked to produce the more "open" become the characters. Our eyes are adapted to the continuous line of a character that has existed since writing began and therefore we have increasingly greater difficulty in decoding dots as they become more separated. Open characters also photocopy poorly, and as you will probably be sending photocopies to a journal this is another point to keep in mind. The final manuscript should be produced at the slowest speed (not draft speed) of which the printer is capable. It may seem trite advice, but you or your secretary will still need to make sure, as with a conventional typewriter, that the ribbon is fresh and the distance between the printer head and the platen is properly adjusted - dot matrix printers are very sensitive to the thickness of paper used.

Most of us think that it is nicer, though not necessarily more efficient, to have a Rolls-Royce rather than a Ford Escort. If you can afford it a laser printer is without the drawbacks of a dot matrix one, but laser printers have their own problems and do not always seem able to produce a text that stands out from the page. A central laser printer for a department is a good idea but usually seems either to be busy with someone else's manuscript or to have been disabled by the activities of the inexperienced person who last used it. There are other upmarket printers, such as the IBM Quietwriter, which generate immaculate text but do so rather slowly by comparison with a dot matrix machine. Speed is rarely an issue in producing a manuscript so, if you can afford it, it is possible to impress the editor by buying the more expensive equipment. I think this is worth it.

\section{Style of type}

The style of type is partly linked, as I have already indicated, to the use of dot matrix printers. All modern combinations of word processing package and printer can produce a great variety of different sizes and styles of type. Remember, however, that in the past most typescripts were produced at 12 characters to the inch, usually in roman or sans serif style (fig 3). We are therefore most familiar with these, and radical departures tend to induce jaundice in the conservative eye. Fancy typefaces are generally to be avoided. I do 


\section{This is sans serif}

not know of any evidence that indicates that they are more legible, except that a large size may help the visually handicapped. Most editors do not belong in this class, at least physically.

\section{Widows and orphans}

It is an irritation though a minor one, to find that a heading or subheading appears on the last line of a page and the subsequent text at the top of the next. Similarly, if the first line of a quotation is the last line of a page it seems disjointed to the reader. Both disrupt the smooth flow of reading. They are a particular feature of word processed text because any revisions alter the whole manuscript beyond, displacing it up or down depending on whether things are deleted or inserted. This changes the position of the manuscript on the page breaks that the processor package automatically inserts according to the instructions it has been given about page length. If you do make such changes-and it is rare when this is not the case-you must look at the whole manuscript beyond the change to make sure that widows and orphans have not suddenly appeared.

\section{Conclusion}

Over the years since computer driven word processing began to take over the production of manuscripts for publication it has been interesting to see how much emotional capital gets invested in individual systems. The result has tended to be a written version of the tower of Babel. In addition, discussions of the various merits and demerits of individual systems have, at dinner tables and editorial meetings, become second only to those of carsusually in terms of "mine is the best and most suited to the task; you really ought to have one because it has all the things that other systems (particularly yours) lack." All of us as writers need to try to get behind this rather immature approach to concentrate on getting to know our writing tool just as in the past we chose to draft in the most elegant and economical way with the materials then available. We should be less concerned with the means than with the finished product.

1 Ainslic J. How to choose a word processor. Br Med J 1989;298:514-5.

\section{Notes from a country doctor}

\section{Constance E Putnam}

The small village of Lyme, New Hampshire, lies south the Connecticut River divides New Hampshire from Vermont. Dartmouth Medical School and the Mary Hitchcock Memorial Hospital are ten miles to the south, in Hanover.

In 1935 the town of Lyme, which had a population of about 900 , had been without a doctor for some time. Despite the great depression residents voted at a town meeting to raise $\$ 500$ for the support of a doctor for the ensuing year.

Bill Putnam was finishing an 18 month internship at the Mary Hitchcock Memorial Hospital when the vacancy in Lyme came to his attention. The position was ideal for his requirements; as a 9 year old he had barely escaped death in the influenza epidemic of 1918 and, inspired by his attending physician, had decided then to become a doctor in a small New Hampshire town. And so it was that on 1 January 1936 William F Putnam MD hung out his shingle-or put up his plate-in Lyme, having made his first house call the night before.

"Doc Putnam" had begun his career. He stayed in Lyme for 42 years, and his practice expanded to include 24 communities in two states. He once calculated that his territory encompassed more than 1000 square miles. Undeterred by a schedule that often allowed him little sleep, Dr Putnam maintained an extensive correspondence with friends and family. $\mathrm{He}$ wrote to them in the early morning, or he used a dictating machine in his car while he was making house calls. The result is a remarkably detailed epistolary record of a medical career. Below are excerpts, chosen at 10 year intervals, from a few of those letters.

Constance E Putnam is one of Dr Putnam's six children. A professional writer and editor, she lives in Concord, Massachusetts.

\section{January 1939}

The first call was on the River Road, which was extremely icy and slippery.... I did a lumbar puncture, part of the process of keeping track of . . . syphilis cases. ... west of the White Mountains; two miles further west

I [next] treated a case of hemorrhoids. That doesn't sound very interesting, but it is, for the patient had had serious trouble with it for over thirty years and never realized that anything could be done for it without operation. Now she is so pleased with the result that she says it was worth waiting thirty years!

The third call was to see a baby he had delivered six weeks earlier.

I had my difficulties there, for the baby's sixteen-year-old mother is not over supplied with brains.... I explained in considerable detail and in words of one syllable that she was to nurse the baby fifteen minutes and then give it as much formula... as the baby would take. As soon as I had completed my explanation she asked me in the tone of voice of one introducing an entirely new subject, "Well, do I feed him from the bottle besides nursing him?"...I haven't the slightest idea what that baby will get to eat.

After some fifty miles and several more calls the doctor arrived home "a little before seven to find six patients waiting ... suffering from iodine burn, syphilis, pregnancy, constipation, metrorrhagia, and foreign body in the eye."

\section{June 1939}

The medical variety continued unabated. Days before his 30th birthday the doctor wrote of "A quiet Sunday afternoon" with "the usual type of interruption - a procession of five unexpected patients winding up with one expected one ... : abscess of thumb, chicken pox, menopausal disturbance, poison ivy, blood test and examination for hairdresser's license, and pregnancy."

\section{January 1949}

A decade later the dominant theme of the letters was the need to juggle activities to fit the available time. 